\title{
A CONSTRUÇÃO DISCURSIVA SOBRE O CONCEITO DE DESENVOLVIMENTO SUSTENTÁVEL
}

\author{
Ivone dos Santos Siqueira ${ }^{1}$ \\ Thaiane Soeiro Dias ${ }^{2}$ \\ Guilherme Francisco Camarinha Neto ${ }^{3}$ \\ Marcelo Augusto Moreno da Silva Alves ${ }^{4}$
}

\begin{abstract}
RESUMO
O artigo apresenta os discursos relativos ao conceito de Desenvolvimento Sustentável partindo da Crise Ambiental, o marco histórico relativo ao conceito em questão, além de explicitar e discutir teses e dissertações que tratam do conceito de desenvolvimento sustentável partindo de uma análise dos discursos que incluem representações e interpretações que se fazem discursos veiculados pela mídia jornalística tendo como referência as publicações de periódicos científicos, teses e dissertações, que compreendem o período de 2010 a 2019. A análise dos dados gerou duas categorias: Discursos sobre Desenvolvimento Sustentável na perspectiva do Desenvolvimento Econômico presente na mídia e os discursos de Desenvolvimento Sustentável na exploração de recursos naturais. Os discursos apresentados vinculam o conceito de desenvolvimento econômico à lógica capitalista do desenvolvimento econômico.
\end{abstract}

Palavras-chaves: desenvolvimento sustentável; crise ambiental; capitalismo; desenvolvimento econômico.

\begin{abstract}
This article presents discourses related to the Sustainable Development concept starting from the Environmental Crisis, the historical milestone related to the concept in question, as well as explaining and discussing theses and dissertations that deal with the concept of sustainable development based on analysis of discourses that include representations e interpretations that are made discourses published by the journalistic media having as reference the publications of scientific journals, theses and dissertations, that comprise the period from 2010 to 2019. Data analysis generated two categories: discourses on Sustainable Development from the perspective of economic development presente in the media and the discourses of sustainable development in the exploitation of natural resources. The discourses presented link the concept of economic development to the capitalist logic of economic development.
\end{abstract}

Keywords: sustainable development; environmental crisis; capitalist; economic development.

Submetido em: 19.03 .2020

Aprovado em: 31.03 .2020

\footnotetext{
1 Doutoranda em Educação em Ciências e Matemática na UFPA- Belém Pará. E-mail: ivone.siqueiraifpa@gmail.com

${ }^{2}$ Doutoranda em Ciências Ambientais na UFPA - Belém Pará.

${ }^{3}$ Doutorando em Ciências Ambientais na UFPA - Belém Pará.

${ }^{4}$ Doutorando em Ciências Ambientais na UFPA - Belém Pará.
} 


\section{INTRODUÇÃO}

O modelo de civilização baseado no capitalismo pós-guerra triunfou quase em escala global, ao mesmo passo em que crescia a consciência de que seus princípios equivocados de desenvolvimento, custavam um preço muito alto, tanto em aspectos sociais e culturais, quanto nas questões ambientais.

O movimento recente do ambientalismo e os debates internacionais sobre a temática foram fortemente influenciados pela literatura científica, destaca-se as publicações do livro "Silent Spring” (1962) (Primavera Silenciosa), da Bióloga Rachel Carson, e do relatório do Clube de Roma, intitulado "The Limits to Growth"(1972) (Os limites do crescimento). Ambos se tornaram os principais símbolos do ambientalismo, que nas décadas seguintes entraria na agenda internacional sobre desenvolvimento econômico e a problemática ambiental.

Mesmo não existindo o termo desenvolvimento sustentável, a percepção de que o modelo socioeconômico dos "centros" implica a depredação dos recursos naturais e a degradação do meio ambiente, entre outras coisas, reforçou a convicção da necessidade de um modelo alternativo de desenvolvimento, o que iria nortear os documentos ambientais sustentados pela ONU a partir de 1980 (CEPAL, 2012).

Contudo, em 1972, o Massachusetts Institute of Technology(MIT) publicou o livro "The Limits to Growth" (Os Limites do Crescimento), um estudo encomendado pelo Clube de Roma, que em tom pessimista, advertia que o ritmo incessante do crescimento econômico e populacional levaria ao colapso global em algum momento do século XXI. "Os Limites do Crescimento", ou simplesmente "Relatório Meadows" tornou-se um dos mais pungentes símbolos do movimento ecológico. Sua imensa divulgação levou a problemática ambiental à um plano visível, colocando definitivamente a questão ambiental na agenda política internacional (OLIVEIRA 2007). Embora a proposta de "crescimento zero" tem gerado profundas controvérsias, que de acordo Perroux (1981), contrariava os próprios fundamentos do capitalismo, constituindo um esmagamento das pretensões de desenvolvimento dos países periféricos, a obra "O Limite do crescimento" destacou-se principalmente pelo pioneirismo em relacionar o meio ambiente com desenvolvimento econômico, que se tornaria a âncora da Conferência de Estocolmo, 1972 (BRAUN, 2005).

A primeira fase do processo de formação das noções de desenvolvimento sustentável refletia a ideia de que os problemas referentes à sustentabilidade não podem ser analisados de 
forma pontual, tendo como ponto de partida, ainda na década de 1970 a Conferência de Estocolmo, primeira reunião oficial a tratar das questões ambientais no âmbito mundial. Nessa época, acreditava-se que a modernização dos processos produtivos seria suficiente para resolver os problemas ambientais e que a solução dependia apenas da legislação e de técnicas de controle de poluição (estratégia que ficou conhecida como "comando-controle"), conforme postulavam os representantes dos países industrializados. No entanto, percebeu-se ao longo do tempo, que seria necessária uma abordagem mais ampla dos problemas e das soluções, discutindo-se, necessariamente, o modelo de desenvolvimento internacional.

Os elementos centrais do conceito de desenvolvimento sustentável seriam formalizados anos depois com a publicação do Relatório Brundtland (1987), sugestivamente intitulado "Nosso Futuro Comum" (Our Common Future,1987), que propunha um processo de alinhamento dos interesses econômicos com a questão ambiental, sendo a combinação entre a ideia do desenvolvimento sustentável e a nova ordem hegemônica do neoliberalismo econômico (OLIVEIRA, 2007). Esse conceito foi decisivo para se repensar as dimensões do desenvolvimento e para a conscientização da sociedade, questionando se as práticas econômicas e sociais desenvolvidas até então não estavam limitando a capacidade dos ambientes naturais de suportar a vida no planeta. Assim, começava a se discutir se o modelo de desenvolvimento adotado seria insustentável ao logo do tempo, comprometendo a vida de futuras gerações (WEBER, 1997).

Já na década de 1990, a elaboração da Agenda 21, na conferência das Nações Unidas sobre meio ambiente no Rio de Janeiro, em 1992, contribuiu para impulsionar a criação de abordagens territoriais a partir de redes de comunicação, buscando-se soluções para os problemas referentes à sustentabilidade e à tentativa de conciliar o crescimento econômico com o desenvolvimento. Assim, ampliou-se a consciência de que os problemas ambientais não são assunto de um setor restrito da economia ou da sociedade nem se restringem aos danos causados ao ambiente físico natural, mas envolvem as relações sociais em um determinado território. Como reflexo da Agenda 21, surgiu uma grande necessidade de geração e divulgação de informações para a resolução de problemas locais.

Ademais, torna-se pertinente comparar as duas obras que influenciaram diretamente a Conferência das Nações Unidas sobre Meio Ambiente Humano, em Estocolmo, 1972 ("Limites do Crescimento") e a Conferência das Nações Unidas sobre Meio Ambiente e Desenvolvimento, no Rio de Janeiro, em 1992 ("Nosso Futuro Comum”). O “Nosso Futuro Comum" pretendeu mostrar que o crescimento é possível desde que todos os países, especialmente da periferia, sigam suas normas, em oposição ao Limites do Crescimento, que 
revelava os interesses dos países centrais em manter a divisão territorial do trabalho e também os conflitos e as contradições entre o "norte desenvolvido" e o "sul subdesenvolvido".

A concepção de desenvolvimento sustentável, segundo Henri Acselrad (2000), é a fórmula encontrada para responder aos impactos negativos do progresso industrialista, incorporando o capital ambiental e abandonando a visão de que a natureza é um bem livre e dando à mesma um preço justo.

Em 2006, Relatório Stern, que tratou dos efeitos das alterações climáticas na economia entre outros, definiu que "desenvolvimento sustentável" e "sustentabilidade" nada mais eram que criar condições econômicas de vida e a sobrevivência do planeta. No mesmo ano o documentário, Uma verdade inconveniente, de autoria Al Gore vice-presidente dos Estados Unidos à época e contrário à política ambiental de W. Bush, que foi presidente dos EUA no período de 2001-2009 . O documentário apresenta as mudanças climáticas e as consequências catastróficas para todo o planeta.

Nas décadas seguintes, a reflexão sobre os estilos de desenvolvimento e a evolução dos padrões de produção e consumo assumiu uma posição central nas grandes cúpulas de desenvolvimento, desde a Cúpula da Terra (1992) até a Conferência das Nações Unidas sobre Desenvolvimento Sustentável (Rio+20) (2012).

O Conceito de Desenvolvimento sustentável surgiu no bojo das preocupações com a degradação ambiental. O conceito de desenvolvimento sustentável tem um de seus maiores marcos no ano de 1987, a partir da divulgação pela Comissão de Bruntland do relatório Our Common Future (Nosso Futuro Comum). Essa comissão foi a responsável pela definição do conceito de desenvolvimento sustentável que é "Desenvolvimento econômico e social que atenda as necessidades da geração atual sem comprometer a habilidade das gerações futuras atenderem a suas próprias necessidades. O Relatório acrescenta ainda que "satisfazer as necessidades e aspirações humanas é o principal objetivo do desenvolvimento sustentável”. (BRUNTLAND, 1987).

No Brasil, as discussões sobre as questões ambientais têm início com a Conferência das Nações Unidas sobre o Meio Ambiente e Desenvolvimento, que ficou conhecida como Rio 92 ou Eco 92. Durante essa Conferência foi redigido o documento Agenda 21, que se trata de um compromisso internacional no qual os países devem repensar o planejamento e soluções para problemas socioambientais. 


\section{METODOLOGIA}

Os discursos do conceito de desenvolvimento sustentável foram obtidos a partir de produções científicas materializadas em dissertações e teses cujas produções ocorreram no período de 2010 a 2019. O levantamento inicial compreendeu as dissertações e teses que analisaram o conceito de desenvolvimento numa perspectiva crítica, as quais somaram vinte e seis produções sendo dezoito dissertações e seis teses, perfazendo um total de vinte e seis produções. Num segundo momento refinamos a análise, para as produções que tratavam do discurso do conceito de desenvolvimento sustentável no que obtemos seis produções acadêmicas, sendo três dissertações e seis teses, que discutiam o conceito de desenvolvimento na perspectiva do viés crítico da análise dos discursos.

Essa investigação tem caráter qualitativo, utilizando-se de dissertações e teses defendidas junto a programas de pós-graduação do país, cujas reduções foram disponibilizadas pela Biblioteca Digital Brasileira de Teses e Dissertações (BDTD), do Instituto Brasileiro de Informação Científica e Tecnológica (IBICT) ${ }^{5}$. Essas produções contribuíram para a contextualização, problematização e construção de um quadro teórico referente aos discursos do conceito de desenvolvimento sustentável referente ao período investigado (ALVES-MAZZOTTI, 2002).

As dissertações e teses foram selecionadas a partir das palavras-chave "análise crítica”, “desenvolvimento sustentável”, “desenvolvimento econômico", “discursos sobre desenvolvimento sustentável". O título das produções e os resumos foram lidos, para que pudessem ser selecionados as dissertações e teses.

A partir da leitura detalhada dos resumos, selecionamos teses e dissertações dos últimos dez anos por considerá-las as mais recentes e representar um período significativo de produções referentes a temática investigada. Os textos completos foram analisados tendo em vista conhecer os discursos eu envolvem o conceito de desenvolvimento sustentável.

A análise dos dados adotada nesta investigação foi a análise de conteúdo do tipo temática, tendo como referência Bardin (2011). Tendo em vista a análise de conteúdo consideramos as fases: pré-análise; a exploração do material; o tratamento dos resultados, a inferência e a interpretação, que são etapas que envolvem essa metodologia de análise. Dessa

\footnotetext{
${ }^{5}$ Disponível em: http://bdtb.ibict.br/.
} 
forma, os dados foram organizados e agrupados por temáticas, de forma a fazer a sistematização dos mesmos.

Inicialmente a leitura dos resumos objetivou a seleção de produções que tratassem de discussões sobre o conceito de desenvolvimento sustentável por um viés crítico. Essa fase segundo Bardin (2011) é chamada de leitura flutuante. Em seguida, foi identificado os objetivos, bem como os resultados apresentados nas dissertações e teses. Assim, os dados brutos foram organizados de forma a atingir uma representação de conteúdos expressivos referente ao objeto investigado.

De acordo com a NBR6028 (ABNT, 2003, p. 2) "o resumo deve ressaltar o objetivo, o método, os resultados e as conclusões do documento". Tendo em vista essa orientação, nos guiamos na análise dos resumos das dissertações e tese, para a seleção das dissertações e teses que utilizamos neste estudo. A análise temática foi a técnica utilizada, tendo em vista a sistematização das informações obtidas (BARDIN, 2011).

A compreensão dos discursos referentes ao conceito de desenvolvimento sustentável, objeto de estudo dessa investigação, foi possível a partir das orientações de Bogdan \& Biklen que indicam a literatura, o pesquisador e os dados como variáveis a serem consideradas na discussão dos resultados.

\section{RESULTADOS E DISCUSSÕES}

As dissertações e teses defendidas obtidas a partir do Banco de Teses e Dissertações da Capes no período de 2010 a 2019, que abordam o discurso sobre o Desenvolvimento Sustentável sistematizados abaixo:

Quadro 1- Dissertações e Teses sobre Discursos relativos ao conceito de DS, período de 2010-2019.

\begin{tabular}{|l|l|l|l|}
\hline Ano & Título & Autor(a) & T/D \\
\hline 2011 & $\begin{array}{l}\text { O Jornal Nacional e a Crise Ambiental: uma análise crítica } \\
\text { de notícias sobre as mudanças climáticas. }\end{array}$ & Ana aula Zaguetto Alves & D \\
\hline 2012 & $\begin{array}{l}\text { Mídia e Mudanças Climáticas: A cobertura de Veja e } \\
\text { Carta Capital. }\end{array}$ & Joana Araújo Maria & D \\
\hline 2014 & $\begin{array}{l}\text { Integração Energética na América do Sul e o desafio da } \\
\text { promoção do Desenvolvimento Sustentável: uma análise } \\
\text { crítica do discurso. }\end{array}$ & Raiza Gomes Fraga & D \\
\hline
\end{tabular}




\begin{tabular}{|c|c|c|c|}
\hline 2016 & $\begin{array}{l}\text { O Simulacro Ecológico: Fálacia, poder e hegemonia no } \\
\text { discurso de Desenvolvimento Sustentável. }\end{array}$ & Marques Casara & $\mathrm{T}$ \\
\hline 2017 & $\begin{array}{l}\text { Discurso jornalístico: proposta de mapeamento do } \\
\text { Dispositivo Desenvolvimento Sustentável. }\end{array}$ & Noêmia Félix da Silva & $\mathrm{T}$ \\
\hline 2017 & $\begin{array}{l}\text { O Dragão de Itataia: mineração e modos de contestação e } \\
\text { de legitimação dos discursos do desenvolvimento. }\end{array}$ & $\begin{array}{lll}\text { Francisco Hélio } & \text { Monteiro } \\
\text { Junior } & & \end{array}$ & $\mathrm{T}$ \\
\hline
\end{tabular}

Fonte: elaboração dos autores.

A análise das teses e dissertações foi dividida em duas categorias de análise de conteúdo do tipo temática. Essa categorização considerou as fonte de vinculação dos discursos consideradas como fonte de dados das informações obtidas nas teses e dissertações e a correlação fonte, temáticas presentes nos discursos. Dessa forma, as categorias obtidas nessa análise foram: Discursos sobre Desenvolvimento Sustentável na perspectiva do Desenvolvimento Econômico presente na Mídia e os discursos de Desenvolvimento Sustentável na exploração de Recursos Naturais.

\title{
3 DESENVOLVIMENTO SUSTENTÁVEL NA PERSPECTIVA DO DESENVOLVIMENTO ECONÔMICO NA MÍDIA
}

Nos discursos sobre questões ambientais o desenvolvimento sustentável se apresenta como discurso hegemônico que busca "encobrir as relações de exploração e dominação que fazem parte do capitalismo" (ALVES, 2011, p. 16). Os discursos do DS requerem a compreensão de hegemonia e de ideologia que neste estudo se apresenta como:

\begin{abstract}
A hegemonia e a manutenção do poder através mais do consenso do que o uso da força, através da naturalização de ideologias que favorecem a manutenção do poder dos grupos dominantes. Nesse sentido, o discurso opera de maneira ideológica, reproduzindo valores que permitem a continuidade de uma determinada configuração social. No caso desta pesquisa, o discurso de desenvolvimento sustentável, que organiza o debate ambiental segundo a lógica capitalista (ALVES, 2011, p.16).
\end{abstract}

Os discursos analisados por Alves (2011) compreendem um total de sete reportagens do Jornal Nacional sobre mudanças climáticas. Nas reportagens analisadas, o discurso de desenvolvimento sustentável buscava legitimar o desenvolvimento econômico perante a crise ambiental como se este tivesse as condições de sustentabilidade ecológica e social. As reportagens trazem a ciência como a autoridade responsável por apontar as causas e as 
soluções e os agentes políticos e econômicos como sendo os agentes capazes de colocar em prática as soluções.

A sociedade seguindo esse discurso é impelida a combater as mudanças climáticas reproduzindo um discurso baseado no medo. Dessa forma, o discurso de desenvolvimento sustentável se apresenta como uma "cortina de fumaça" que encobre a verdadeira face da crise. Assim, a injustiça social, a ciência e o mercado desvinculados da ética, que são questões que fazem parte do pacote da lógica capitalista são ocultadas do debate pelos meios de comunicação em massa (ALVES, 2011).

A investigação realizada por Maria (2012) também trata de reportagens sobre as mudanças climáticas publicizadas na Revista Veja e Carta Capital. As reportagens faziam a cobertura das questões climáticas desassociando causa, efeito e solução de forma a limitar a percepção do público sobre as variáveis que envolvem as questões climáticas. Com esse artifício gera-se uma leitura acomodada não estimulando o leitor a fazer uma leitura crítica do problema.

Todas as reportagens tiveram a $15^{\text {a }}$ Conferência das Partes, em 2009, também conhecida como Conferência das Nações Unidas sobre as Mudanças Climáticas ocorrida em Conpenhague, como tema principal. As reportagens da Revista Veja dão ênfase na escassez dos recursos ambientais tendo como cerne dos problemas ambientais o excesso de pessoas no mundo. Já a Carta Capital relaciona os problemas ambientais a causas antropocêntricas e trazem o discurso de sustentabilidade evidenciando que é vantajoso reduzir os gases que provocam o efeito estufa. Apesar das leituras diferentes de uma mesma questão, as diferentes mídias partilham o mesmo ponto de vista da questão ambiental como "erro de Percurso" sendo esta inadequação passível de correção dentro do atual modelo de desenvolvimento. $\mathrm{O}$ desenvolvimento aqui é um objetivo a ser alcançado e está veiculado a ideia de progresso moderno (MARIA, 2012).

O conceito de desenvolvimento sustentável ainda se encontra em construção e pode ser visto tanto de forma negativa quanto positiva. A perspectiva positiva indica a tomada de consciência sobre as questões ambientais. Já o lado negativo é a forma como o discurso se religitima de forma que o "sustentável" é capaz de gerar marca a ponto de gerar "lucros simbólicos" (VEIGA, 2008, p. 192).

Nesse conceito, estão embutidos os interesses do mercado, dos negócios. Segundo Fernandes e Guerra (2006), o discurso de desenvolvimento sustentável do ponto de vista teórico parece se opor ao modelo de desenvolvimento econômico dominante. No entanto, essa aparência é um artifício do projeto de desenvolvimento econômico global e o que se chama de 
desenvolvimento sustentável são experiências da aplicação desse projeto (FERNANDES; GUERRA, 2006).

O conceito de desenvolvimento sustentável é a expressão da síntese entre desenvolvimento econômico e meio ambiente. Assim, os países do Norte que ao longo da história conseguiram o desenvolvimento a partir de práticas predatórias em escalas globais agora se autointitulam os guardiões do planeta com a adoção do discurso do desenvolvimento sustentável (BARCELLOS, 2008).

A investigação realizada por Silva (2017) abrange a cobertura da Conferência Rio+20, a partir dos jornais O Globo, Folha de S. Paulo e Estado de S. Paulo. Segundo o referido estudo o Discurso de Desenvolvimento Sustentável enunciado a partir dos jornais objetos de estudo através da produção da notícia atribuem valores que se legitimam na criação de " um "efeito de verdade", apontando para um jornalismo que contribui para a construção de sentidos e uma "verdade" sobre o problema ambiental" (SILVA, 2017, p .350).

\section{OS DISCURSOS DE DESENVOLVIMENTO SUSTENTÁVEL NA EXPLORAÇÃO DE RECURSOS NATURAIS}

Monteiro-Junior (2017) na sua investigação objetivou compreender os modos de contestação e de legitimação do desenvolvimento gestados no tempo de instalação do complexo mínero-industrial de Itataia, por aqueles que conformam um campo de disputa sobre os efeitos decorrentes da operação da mina de urânio e de fosfato, localizada no município de Santa Quitéria, situado no semiárido cearense. O estudo indicou a presença de conflitos nessa relação e evidenciou conflitos socioambientais que resultam do longo processo que antecede a operação da mina colocam em relevo percepções conflitantes sobre a ideia de desenvolvimento. $\mathrm{O}$ autor ao analisar o impacto dos empreendimentos destaca que:

Essa leitura etnocêntrica e enviesada do cenário socioeconômico da região que receberá o PSQ, pode-se dizer, dá início ao processo de desterritorialização empreendido pelo capital globalizado. Esse processo que engloba as práticas de expropriação, precarização e/ou exclusão daqueles que deveriam ser incluídos pela sua incorporação à dinâmica produtiva dos grandes projetos de desenvolvimento desde que fossem asseguradas condições dignas de trabalho e preservação da qualidade dos bens naturais disponíveis, é preparado pelos conflitos discursivos que suscitam sentimento de insegurança e de medo, mas também de resistência e de luta. Ora, a promessa de tantas mudanças positivas para o homem do semiárido que viriam com o PSQ não sobrevive ao crivo mais superficial (MONTEIRO-JUNIOR, 2017, p. 2014) 
A relação que se estabelece coloca a proteção ambiental e, consequentemente, o desenvolvimento socioambiental subordinado às metas de crescimento econômico. "A sustentabilidade, nesse caso, não se encontra dada nos documentos oficiais e muito menos nos procedimentos administrativos balizados por uma ideia de governança global que assume compromissos formais com os aspectos rentáveis do "capitalismo verde" (MONTEIROJUNIOR, 2017, p. 2011).

As instalações dos empreendimentos trazem um discurso de geração de emprego e renda para a população local. No discurso é velado quais tipos de empregos serão gerados e as consequências da chegada de um grande número de trabalhadores não é discutida e menos ainda os impactos ambientais provocados pelo empreendimento.

Os estudos de Fraga (2014) abordam o tema da integração energética na América do Sul e a inserção deste processo em uma estratégia de integração regional. Na investigação foi identificado o discurso representativo da integração energética sul-americana no período entre os anos 2000 e 2010, além de reflexões sobre as possibilidades deste processo representar avanço em direção à promoção do desenvolvimento sustentável. Os grandes empreendimentos com o discurso da integração escondem os interesses da lógica capitalista desconsiderando os conflitos socioambientais locais.

\footnotetext{
Muito embora o projeto do complexo binacional de Garabi esteja alicerçado no campo da integração energética da região sul-americana, principalmente por ser um dos projetos apresentados pela IIRSA, os conflitos socioambientais são sentidos na esfera local podendo passar despercebidos em nível regional em prol de um objetivo maior: a integração da região sul-americana (FRAGA, 2014, p. 129).
}

A investigação a partir dos documentos revelam as contradições entre discurso e a efetivação da proposta que trata do empreendimento.

\begin{abstract}
Observamos certa incongruência entre o discurso da integração energética e seus projetos, pois em documentos como a Declaração de Margarita, a constituição da Unasul e o Plano de Ação para a Integração Energética há referências explícitas ao incentivo ao desenvolvimento de energias renováveis. Porém, na carteira de projetos da IIRSA/Cosiplan exposta no capítulo quatro, só é possível encontrar energia renovável em projetos de hidrelétricas. Assim, o discurso da integração energética que tanto se refere às energias renováveis como elemento central para a promoção do acesso universal à energia e a preservação do meio ambiente, não vem se concretizando no âmbito da Unasul (FRAGA, 2014, p. 133-134).
\end{abstract}

Dessa forma, o estudo conclui o objetivo do projeto do empreendimento, não é a integração energética como propósito de consolidação e aumento da capacidade de geração, transmissão e distribuição de energia e diversificação da matriz energética dos países 
membros e menos ainda uma ferramenta para promover o desenvolvimento sustentável na região.

O capital articula o discurso do desenvolvimento sustentável de forma construída e legitimada, cooptando as pessoas a se unirem no jogo da conservação. Esse jogo consiste em aniquilar os interesses dos sujeitos menos favorecidos, colocando em pé de igualdade na produção e solução dos problemas ambientais. Com isso, surge "o discurso do mutirão, da ação individual do sujeito para salvar o planeta, assumiu dimensões globais". É inegável a importância das ações individuais, mas não ao ponto de ser colocada como única forma de reverter a crise ambiental e salvar o planeta (BARCELLOS, 2008, p.112).

Os estudos de Casara (2016) discutem os discursos de empresas, governos e Organizações não governamentais veiculados por meio mediáticos analisando a mercantilização da natureza e a ecologia-espetáculo nestes discursos.

Os discursos dos agentes investigados vão no sentido de um "bem-intencionado" discurso dos malefícios da poluição. Há um discurso orquestrado em defesa da causa ambiental que transforma os cidadãos em consumidores a partir de uma poderosa estrutura mediática amparada pela máquina de propaganda (CASARA, 2016).

O discurso do conceito de Desenvolvimento Sustentável traz a sustentabilidade como um dispositivo conservador no qual a estrutura insustentável é requintada com um artificialismo técnico-científico, onde a tônica é mais mercado, mais negócios (LIPOVETSKY; SERROY, 2011).

O capital precisa de matérias-primas e de serviços essenciais para a produção de bens. Diante dessa necessidade, o capital amplia sua hegemonia a partir da "escapada hegemônica" com a construção de um discurso de uso racional e sustentável da natureza com o estabelecimento do conceito de desenvolvimento sustentável (BARCELLOS, 2008, p.111).

\section{CONSIDERAÇÕES FINAIS}

O conceito traz em si uma estrutura insustentável. Dessa forma, o termo desenvolvimento econômico sustentável é mais adequado que o conceito de desenvolvimento sustentável, aliás é exatamente este viés econômico que se pretende ocultar. Assim, o sistema tenta a camuflar esses interesses.

O Discurso do Desenvolvimento Sustentável é um sucesso do espetáculo mediático o qual tem a autorização das forças hegemônicas para enganar os espectadores com explicações 
simplistas, para causas estruturais. Assim a população aceita sem contestação que a causa dos problemas ambientais é o aumento populacional.

\section{REFERÊNCIAS}

ABNT. Associação Brasileira de Normas Técnicas. NBR6028: Informação e documentação: resumo: apresentação. Rio de Janeiro, 2003.

ACSELRAD, Henri. Desenvolvimento Sustentável: A Luta por um Conceito. Proposta: Experiências em Educação Popular. Desenvolvimento e Meio Ambiente. Rio de Janeiro, FASE, N. ${ }^{\circ}$ 56, Ano XVII: 5-8, Março/1993.

ALVES, Ana aula Zaguetto. O Jornal Nacional e a Crise Ambiental: uma análise crítia de notícias sobre as mudanças climáticas. Dissertação (Mestrado). Escola Superior de Agricultura Luis de Queiroz. 2011.

ALVES-MAZZOTTI, A. J. A "revisão bibliográfica" em teses e dissertações: meus tipos inesquecíveis - o retorno. In: BIANCHETTI, L.; MACHADO, A. M. N. (Org.). A bússula do escrever: desafios e estratégias na orientação de teses e dissertações. São Paulo: Cortez, 2002.

BARDIN, L. Análise de conteúdo. Lisboa: Edições 70, 2011.

BRAUN, RICARDO. Novos Paradigmas Ambientais: Desenvolvimento ao ponto sustentável. Petrópolis, RJ: Vozes, 2005.

BOGDAN, R.; BIKLEN, S. Investigação qualitativa em educação: uma introdução à teoria e aos métodos. Porto, Portugal: Porto Editora,1994.

CASARA, Marques. O Simulacro Ecológico: Fálacia, poder e hegemonia no discurso de Desenvolvimento Sustentável. Tese (Doutorado). Pontifícia Universidade Católica de São Paulo, Programa de Pós-graduação em Comunicação e Semiótica. 2016.

FERNANDES, Marcionila; GUERRA, Lemuel. Contra-discurso do desenvolvimento sustentável. 2 ed. Ver. Belém: Associação de Universidades Amazônicas, Universidade Federal do Pará. Núcleo de Altos Estudos Amazônicos, 2006.

FRAGA, Raiza Gomes. Integração Energética na América do Sul e o desafio da promoção do Desenvolvimento Sustentável: uma análise crítica do discurso.

Universidade de Brasília. Centro de Desenvolvimento Sustentável. 2014.

LÉNA, Philippe; NASCIMENTO, Elimar Pinheiro do. Enfrentando os limites do crescimento: sustentabilidade, decrescimento e prosperidade. Rio de Janeiro, Garamond, 2012.

LIPOVETSKY, G.; SERROY, J. A cultura-mundo: resposta a uma sociedade desorientada. São Paulo: Companhia das Letras. 2011. 
MARIA, Joana Araújo. Mídia e Mudanças Climáticas: A cobertura de Veja e Carta Capital. Dissertação (Mestrado). Universidade de Brasília. Centro de Desenvolvimento Sustentável. 2012.

MONTEIRO-JUNIOR, Francisco Hélio. O Dragão de Itataia: mineração e modos de contestação e de legitimação dos discursos do desenvolvimento. Tese (Doutorado).

Universidade Federal do Ceará, Centro de Humanidades. 2017.

SILVA, Noêmia Félix da. Discurso jornalístico: proposta de mapeamento do Dispositivo Desenvolvimento Sustentável. Tese (Doutorado). Universidade de Brasília. Faculdade de Comunicação. 2017.

VEIGA, José Eli. Desenvolvimento sustentável: o desáfio do século XXI. 3 ed. Rio de Janeiro: Garamond. 2008. 